[3] — Electronic Circuits, 2nd ed. New York: McGraw-Hill, 1964, ch. 14.

[4] — Electronics: BJT's, FET's, and Microcircuits. New York: McGraw-Hill, 1969. ch. 12.

[5] A. S. Sedra and K. C. Smith, Microelectronic Circuits, 2nd ed. New York: Holt, Rinehart and Winston, 1987, p. 51.

\section{Archimedes' Principle as an Application of the Divergence Theorem}

\author{
AYHAN ALTINTAS
}

\begin{abstract}
One can obtain Archimedes' principle as an application of the divergence theorem, which makes the theorem more physically appealing.
\end{abstract}

The divergence theorem [1]

$$
\oint_{S} \boldsymbol{F} \cdot d \boldsymbol{S}=\int_{V} \nabla \cdot F d v
$$

relates the total flux of a vector field $F$ through a closed surface $S$ to the volume integral of the divergence of the field over the volume $V$ of the surface $S$. The surface normal in $d S=\hat{n} d S$ is directed outward in (1).

Even though the divergence theorem is given in almost every calculus and electromagnetics book, its meaning is still quite abstract to some students. On the other hand, Archimedes' principle [2] is familiar to students much earlier than the college education. One can apply the divergence theorem to obtain Archimedes' Principle, which makes the theorem more physically appealing.

Let us have an object of volume $V$ and surface $S$, immersed in a vessel filled with fluid of density $m$ (see Fig. 1). The pressure field $p$ in the fluid is a function of the distance from the top level of the fluid, so

$$
p=-m g z+p_{0}
$$

where $g$ is the gravitational acceleration and $z$ is the distance measured along $\hat{z}$-coordinate. The constant $p_{0}$ is added to represent the atmospheric pressure although its inclusion does not affect the result. If we define a vector field

$$
\boldsymbol{F}=-p \hat{z}
$$

then, $\boldsymbol{F} \cdot \boldsymbol{d} \boldsymbol{S}$ is the $\hat{z}$ component of the force on $\boldsymbol{d S}$ due to the pressure. It is clear that LHS of (1) is the total lift due to the pressure. The RHS is calculated using $\nabla \cdot \boldsymbol{F}=m g$,

$$
\int_{V} \nabla \cdot \boldsymbol{F} d v=m g \int_{V} d v=m g V
$$

which is the weight of the liquid in $V$. Thus, one obtains the Archimedes' principle.

Manuscript received September 7, 1988.

The author is with the Department of Electrical and Electronics Engineering, Bilkent University, Ankara, Turkey.

IEEE Log Number 9034650.

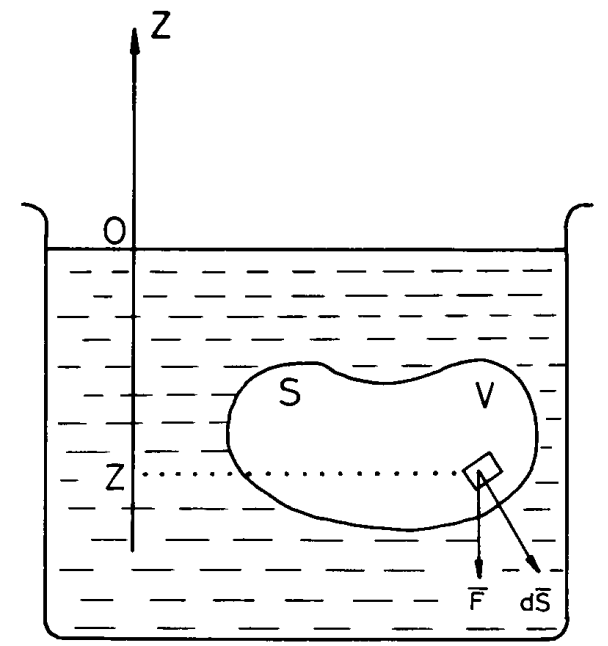

Fig. 1. An object of volume $V$ and surtace $s$ immersed in a liquid.

\section{REFERENCES}

[1] G. B. Thomas, Jr. and R. L. Finney, Calculus and Analytic Geometry. Reading, MA: Addison Wesley, 1984, pp. 975-979.

[2] D. Halliday and R. Resnick, Fundamentals of Physics. New York: Wiley, 1970, pp. 281-282.

\section{Comments on "Comparison of Ampere's Law (ACL) and the Law of Biot-Savart (LBS)"}

JOSÉ MARGINEDA AND PAUL LORRAIN

\begin{abstract}
We agree with the author of the quoted paper ${ }^{1}$ that the application of Ampere's circuital law can cause confusion in the minds of students. However, Section III of his paper further confuses the issue and creates problems that are worse than the one that he tries to solve.
\end{abstract}

We agree with Kalhor ${ }^{1}$ in that the application of Ampère's circuital law (ACL) is sometimes a source of confusion for students. The case of the square loop is a good example, as his paper shows.

As the author says, Equation (4)

$$
\boldsymbol{B}=\boldsymbol{a}_{z} \frac{2 \mu_{0} I}{\pi a}
$$

is incorrect because it results from an incorrect application of Ampere's law. However, the correct explanation of the error is simpler than the one proposed in his paper. It runs as follows.

Manuscript received November 10, 1988.

J. Margineda is with the Departamento de Física Aplicada, Universidad de Murcia, 30071 Murcia, Spain.

P. Lorrain is with the Department of Geological Sciences, McGill University, Montreal, Quebec, Canada.

IEEE Log Number 9034654.

'H. A. Kalhor, IEEE Trans. Education, vol. E-31, pp. 236-238, Aug. $198 \mathrm{~s}$.

0018-9359/90/0500-0222\$01.00 (C 1990 IEEE 